Check for updates

Cite this: Chem. Sci., 2019, 10, 5539

๑ All publication charges for this article have been paid for by the Royal Society of Chemistry

Received 31st January 2019

Accepted 25th April 2019

DOI: $10.1039 / \mathrm{c} 9 \mathrm{sc} 00561 \mathrm{~g}$

rsc.li/chemical-science

\section{Tuning ligand field strength with pendent Lewis acids: access to high spin iron hydrides $\uparrow$}

\author{
John J. Kiernicki, ${ }^{a}$ James P. Shanahan, ${ }^{a}$ Matthias Zeller ${ }^{b}$ \\ and Nathaniel K. Szymczak (D) *a
}

\begin{abstract}
Geometrically flexible 9-borabicyclo[3.3.1]nonyl units within the secondary coordination sphere enable isolation of high-spin Fe(॥)-dihydrides stabilized by boron-hydride interactions and a rare example of an isolable $S=3 / 2$ reduction product. The borane-capped Fe(I)-dihydride: (1) rapidly deprotonates $E-H(E$ $=\mathrm{N}, \mathrm{O}, \mathrm{P}, \mathrm{S}$ ) bonds to afford borane-stabilized Fe adducts and (2) releases $\mathrm{H}_{2}$ upon exposure to $\pi$-acids. The Lewis acids provide an avenue for redox-leveling in analogy to the near constant operating potential for $\mathrm{N}_{2}$ reduction in nitrogenase.
\end{abstract}

Iron-dihydrides are intermediates in myriad homogenous catalytic reactions and the recent push to develop earthabundant transition metal catalysts has fueled many research groups to explore their reactivity. ${ }^{1}$ Beyond relevance to homogenous catalysis, iron-dihydrides have been implicated in biological reduction sequences. Whereas strong-field hydride ligands typically enforce low-spin configurations, metallocofactors including nitrogenase contain high-spin hydrides. ${ }^{2}$ To account for the modest conditions used by nitrogenase enzymes for $\mathrm{N}_{2}$ reduction, one proposal to accumulate reducing power at a near constant potential is to store reducing equivalents as $\mathrm{Fe}-\mu-\mathrm{H}-\mathrm{Fe}$ intermediates. ${ }^{2,3}$ For example, the $\mathrm{E}_{4}$ state of the FeMoco center of nitrogenase is proposed to eliminate $\mathrm{H}_{2}$ from accumulated bridging hydrides concomitant with $\mathrm{N}_{2}$ binding/reduction (Fig. 1).

Well characterized synthetic examples of open-shell Fe- $\mu-\mathrm{H}^{-}$ $\mathrm{Fe}$ complexes are rare, ${ }^{4}$ and thus, despite their relevance in biology, the synthesis and reactivity of such species remain largely unknown. This disparity is likely due to the mismatched requirements of the ligand/metal combination - strong-field hydride donor ligands rarely afford high-spin electronic configurations.

Our group is working to evaluate how the precise structural, electronic, and cooperative modes in the secondary coordination sphere can be used to regulate reactivity. ${ }^{5}$ One way in which the ligand-field strength of otherwise strong-field hydride ligands can be attenuated (accommodating high-spin states) is by introducing acidic groups to form bridging hydrides. The

aUniversity of Michigan, 930 N. University, Ann Arbor, MI 48109, USA. E-mail: nszym@ umich.edu

${ }^{b}$ H. C. Brown Laboratory, Purdue University, 560 Oval Dr, West Lafayette, IN 47907, USA

$\dagger$ Electronic supplementary information (ESI) available. CCDC 1884220-1884232 and 1903500. For ESI and crystallographic data in CIF or other electronic format see DOI: $10.1039 / \mathrm{c} 9 \mathrm{sc} 00561 \mathrm{~g}$ multiple Fe-centers in the $\mathrm{E}_{4}$ state may serve this role. ${ }^{6}$ To model these intermediates with redox-inactive acids, we targeted the synthesis of ferrous-dihydride compounds in the presence of appended boron Lewis acids. Herein, we report Lewis acid enabled isolation of a high-spin Fe(II)-di(boro)hydride as well as its reduction product, an $S=3 / 2$ Fe-di(boro)hydride, and subsequent reactivity.

The complex, $\left({ }^{\mathrm{BBN}} \mathrm{PDP}^{\mathrm{tBu}}\right) \mathrm{FeBr}_{2}$, contains a pair of moderately acidic 9-borabicyclo[3.3.1] nonyl (9-BBN) substituents that are capable of interacting with nitrogenous substrates independent of the metal center $\left(\mathrm{N}_{2} \mathrm{H}_{4}\right)$ or cooperatively with the metal center $\left(\mathrm{NH}_{2}{ }^{-}\right) .^{7}$ Treatment of a freshly-thawed orange THF solution of $\left({ }^{\mathrm{BBN}} \mathrm{PDP}^{\mathrm{BBu}}\right) \mathrm{FeBr}_{2}$ with two equiv. $\mathrm{KBHEt}_{3}$ affords an olive-tan powder, assigned as $\left({ }^{\mathrm{BBN}} \mathrm{PDP}^{t \mathrm{Bu}}\right) \mathrm{FeH}_{2}$ (1) $(70 \%$, Fig. 2). $\mathbf{1}$ is modestly stable with a half-life of $\sim 24 \mathrm{~h}$ in THF at room temperature. Investigation by ${ }^{1} \mathrm{H}-\mathrm{NMR}$ spectroscopy (THF) revealed a paramagnetically shifted spectrum with resonances ranging $-16.9-63.6 \mathrm{ppm}$. The decrease in solution symmetry

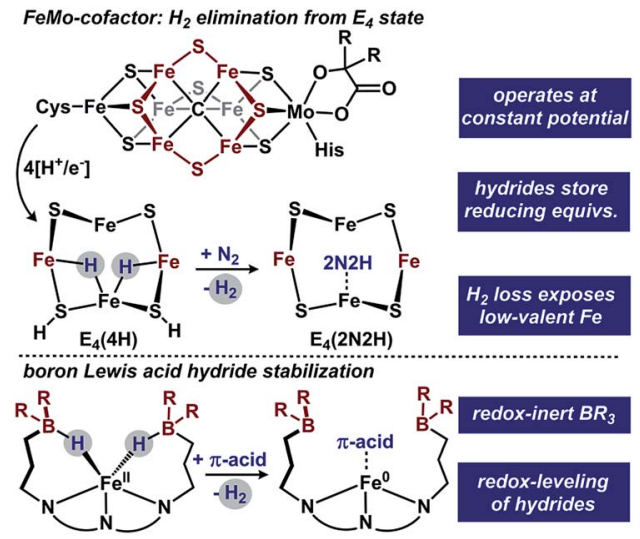

Fig. 1 FeMo-cofactor and our approach to hydride accumulation with boron Lewis acids. 

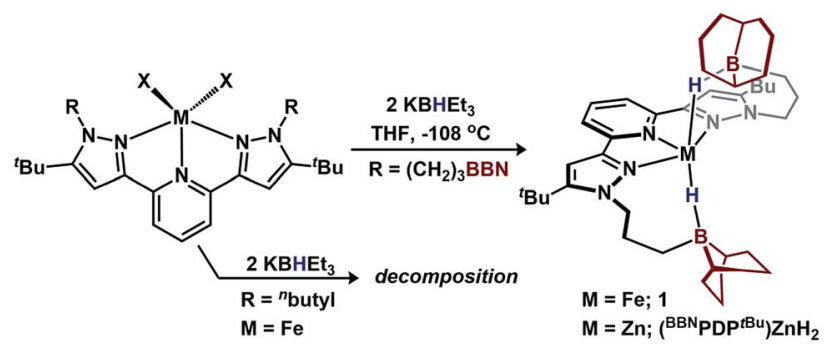

Fig. 2 Synthesis of borane-capped metal-dihydrides.

from $C_{2 \mathrm{v}}$ to $C_{2}$ is consistent with the trialkylboranes interacting with the hydride ligands at the Fe-center. Infrared spectroscopy ( $\mathrm{KBr}$ ) supported this formulation with a broad $\mathrm{Fe}-\mathrm{H}-\mathrm{B}$ stretch at $\sim 1839 \mathrm{~cm}^{-1}$. $^{8}$ Notably, the energy of this absorption is at significantly lower energy than bis(tris(mercaptoimidazolyl) hydroborato)-Fe(II) species that display a bridging borohydride. ${ }^{9}$ Solution magnetic susceptibly studies $\left(25^{\circ} \mathrm{C}\right.$, THF) establish 1 as high-spin Fe(II) $\left(\mu_{\text {eff }}=4.6 \pm 0.2 \mu_{\mathrm{B}}\right)$.

Single-crystal X-ray diffraction (XRD) experiments confirmed 1 as an iron-dihydride with each hydride capped by pyramidalized trialkylboranes $\left(\mathrm{Fe}-\mathrm{B}=2.970 \AA \stackrel{\circ}{\mathrm{A}} \sum \mathrm{B}_{\alpha}=318.6^{\circ}\right.$;

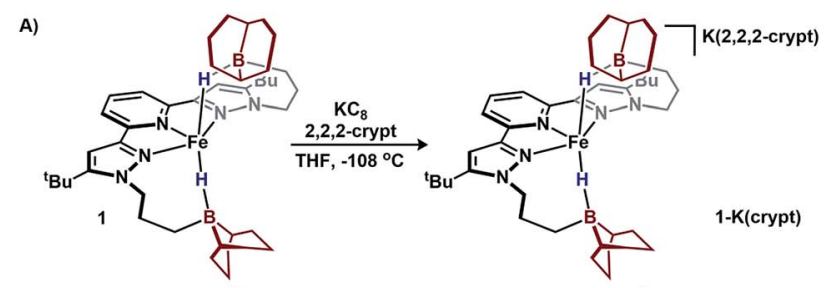

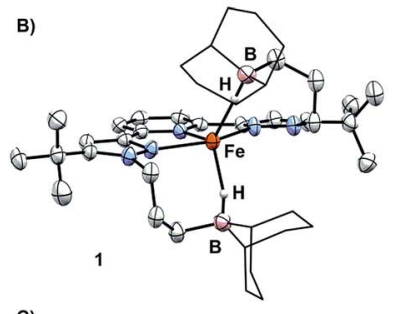

C)

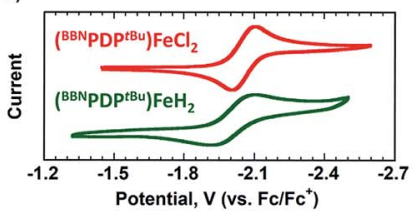

E)

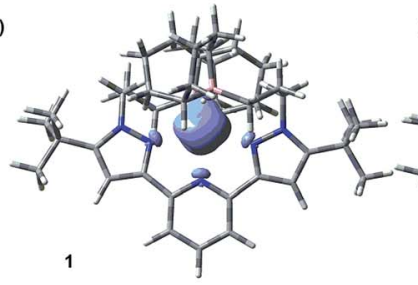
D)
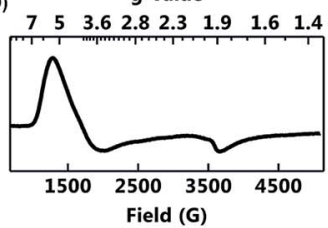

F)

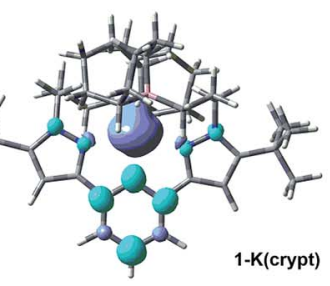

Fig. 3 (A) Reduction of 1. (B) Molecular structures of 1 and 1-K(crypt) (50\% probability ellipsoids). For clarity, the 9 -BBN substituents are displayed in wireframe. (C) Electrochemical comparison between 1 and $\left({ }^{\mathrm{BBN}} \mathrm{PDP}^{t \mathrm{Bu}}\right) \mathrm{FeCl}_{2}$. (D) X-band EPR of 1-K(crypt) at $10 \mathrm{~K}$ in $1: 1$ toluene/THF. (E and F) Spin-density isosurface plots (0.002 a.u.) of 1 and $1-K($ crypt), respectively.
Fig. 3B). The geometry about iron is best described as square pyramidal $\left(\tau_{5}=0.31\right)$. Complex 1 is a rare example of a monometallic high-spin Fe(II)-dihydride (or Fe(II)-diborohydride). ${ }^{\mathbf{a}, \boldsymbol{6} \boldsymbol{c}, \boldsymbol{9}}$

The requirements of the intramolecular acids to stabilize 1 were assessed with a control ligand, ${ }^{\mathrm{Bu}} \mathrm{PDP}^{t \mathrm{Bu}}$, where the $-\left(\mathrm{CH}_{2}\right)_{3} \mathrm{BBN}$ fragments are replaced with $n$-butyl groups (Fig. 2). ${ }^{7}$ Treating ( $\left.{ }^{\mathrm{Bu}} \mathrm{PDP}^{t \mathrm{Bu}}\right) \mathrm{FeBr}_{2}$ with 2 equiv. $\mathrm{KBHEt}_{3}$ afforded intractable mixtures, precluding characterization (see ESI $\dagger$ ). We propose that the appended trialkylboranes in 1 serve two important roles: (1) to stabilize the hydride ligands, and (2) to decrease the entropic penalty for stabilization (intramolecular 9-BBN vs. exogenous $\mathrm{BEt}_{3}$ ). Attempts to install another donor ligand to $\mathbf{1}$ and enforce a low-spin configuration were unsuccessful: 1 was unreactive toward stoichiometric 1,4diazabicyclo[2.2.2] octane, $\mathrm{NMe}_{3}$, and $\mathrm{PMe}_{3}$, but decomposed when treated with 4-dimethylaminopyridine.

To assess the requirements of the metal center and provide additional spectroscopic characterization, we synthesized the zinc analogue, $\left({ }^{\mathrm{BBN}} \mathrm{PDP}^{t \mathrm{Bu}}\right) \mathrm{ZnH}_{2}$, from $\left({ }^{\mathrm{BBN}} \mathrm{PDP}^{t \mathrm{Bu}}\right) \mathrm{ZnI}_{2}$ (Fig. 2). ${ }^{11} \mathrm{~B}-\mathrm{NMR}$ spectroscopy (THF) of $\left({ }^{\mathrm{BBN}} \mathrm{PDP}^{t \mathrm{Bu}}\right) \mathrm{ZnH}_{2}$ revealed an upfield resonance at $5.43 \mathrm{ppm}$, consistent with a tetrahedral boron center. ${ }^{10}$ IR spectroscopy ( $\mathrm{KBr}$ ) revealed a broad $\mathrm{Zn}-\mathrm{H}-\mathrm{B}$ stretch at $\sim 1775 \mathrm{~cm}^{-1}$ that shifts upon deuterium labeling to $\sim 1300 \mathrm{~cm}^{-1} \cdot{ }^{11}{ }^{2} \mathrm{H}-\mathrm{NMR}$ spectroscopy established the assignment of the hydride resonance at $0.65 \mathrm{ppm}$, which is comparable to other $\kappa^{1}-\mathrm{Zn}\left(\mathrm{BH}_{4}\right) / \mathrm{Zn}\left(\mathrm{BH}_{3} \mathrm{R}\right)$ complexes. ${ }^{12}$ The molecular structure of $\left({ }^{\mathrm{BBN}} \mathrm{PDP}^{t \mathrm{Bu}}\right) \mathrm{ZnH}_{2}$ displays bonding metrics analogous to 1 (see $\mathrm{ESI}_{\dagger} \dagger$ ).

Electrochemical investigation of 1 using cyclic voltammetry $\left(0.2 \mathrm{M}\left[\mathrm{Bu}_{4} \mathrm{~N}\right]\left[\mathrm{PF}_{6}\right], \mathrm{THF}\right)$ revealed a quasi-reversible reductive event at $-2.06 \mathrm{~V} v s$. $\mathrm{Fc} / \mathrm{Fc}^{+}$which is minimally shifted from $\left({ }^{\mathrm{BBN}} \mathrm{PDP}^{t \mathrm{Bu}}\right) \mathrm{FeCl}_{2}(\Delta=+10 \mathrm{mV}),{ }^{13}$ despite their different X-type donors (Fig. 3C). ${ }^{\mathbf{1 4}}$ The similar redox potentials suggest that, in analogy to the $\mathrm{E}_{4}$ state of nitrogenase, reducing equivalents can be delivered at a near constant potential to a Fe(II) state, when stored as bridging hydride equivalents. ${ }^{15}$ To prepare the reduced complex, 1 equiv. of $\mathrm{KC}_{8}$ was added to a freshly thawed THF solution of 1 in the presence of 2,2,2-cryptand, resulting in an immediate color change to a vibrant green species assigned as $[\mathrm{K}(2,2,2$-cryptand $)]\left[\left({ }^{\mathrm{BBN}} \mathrm{PDP}^{t \mathrm{Bu}}\right) \mathrm{FeH}_{2}\right]$ (1-K(crypt); Fig. 3A). ${ }^{\mathbf{1 6}}$ Investigation of 1-K(crypt) by ${ }^{1} \mathrm{H}-\mathrm{NMR}$ spectroscopy (THF) revealed a paramagnetically shifted spectrum with resonances ranging -70.6-95.0 ppm with solution $C_{2}$ symmetry. Samples of 1-K(crypt) are less stable than $\mathbf{1}$ and have an approximate halflife of $12 \mathrm{~h}$ in THF at room temperature. Upon reduction, the Fe-H-B infrared absorption shifts to higher energy $\left(\sim 1866 \mathrm{~cm}^{-1} ; \mathrm{KBr}\right)$. Solution magnetic susceptibly studies $\left(25^{\circ} \mathrm{C}\right.$, THF) of 1-K(crypt) are consistent with an $S=3 / 2$ complex $\left(\mu_{\text {eff }}=4.1 \pm 0.1 \mu_{\mathrm{B}}\right) \cdot{ }^{17} \mathrm{X}$-band EPR spectroscopy was employed to confirm the spin-state. Regardless of coordination environment or geometry, $S=1 / 2$ iron complexes, typically exhibit $g$ values near the free electron value, ${ }^{18}$ while high-spin complexes exhibit $g_{x}$-tensors $>3.5 .^{2,19}$ 1-K(crypt) displays a broad rhombic signal with $g$ values of $5.6,3.97$, and 1.82 at $10 \mathrm{~K}$ in $1: 1 \mathrm{THF} /$ toluene glass (Fig. 3D), which suggests 1-K(crypt) is best described as high-spin. ${ }^{20}$ Reduced iron complexes with low coordination numbers (2, 3, occasionally 4$)$ are often high-spin, ${ }^{19 c, 19 e, 21}$ while 
those stabilized by strong-field ligands (i.e. NHC, porphyrin, phosphines) are low-spin. 1-K(crypt) is a rare example of a highspin complex with a coordination number $\geq 5 .{ }^{19 b}$

For structural comparison, 1-K(crypt) was examined by XRD. Data refinement revealed the anionic portion of 1-K(crypt) to be geometrically similar $\left(\tau_{5}=0.36\right)$ to 1 (Fig. 3B). The interacting trialkylboranes are equidistant from the metal center in $\mathbf{1}$ and 1$\mathbf{K}(\mathbf{c r y p t})$. Upon reduction, the $\mathrm{Fe}-\mathrm{N}_{\text {pyridine }}$ bond distance decreases from 2.178(5) to 2.021(6) consistent with enhanced $\pi$ backbonding. ${ }^{22}$ DFT optimized geometries for the high-spin configuration of $\mathbf{1}$ and $\mathbf{1 - K}$ (crypt) are in agreement with their crystallographic structures. ${ }^{23}$ The spin-density for $\mathbf{1}$ is localized on iron, consistent with a high-spin Fe(II) description (Fig. 3E). For 1-K(crypt), significant spin-density is localized on the pyridyl-moiety of the chelate. The calculated $\beta$-SOMO for 1$\mathbf{K}$ (crypt) corresponding to reduction is primarily comprised of ligand $-\pi^{*}$ orbitals on the pyridyl moiety with minimal $\mathrm{Fe}$ contribution (19\%). This analysis is consistent with reduction of 1 affording an $S=3 / 2$ system through antiferromagnetic coupling of high-spin Fe(II) with $\left[{ }^{\mathrm{BBN}} \mathrm{PDP}^{t \mathrm{Bu}}\right]^{1-} .{ }^{24}$ The calculated electronic structure is consistent with crystallographic bond metrics. ${ }^{25}$ Pyridyl- $\pi$ * population is reflected by $\mathrm{C}_{3}-\mathrm{C}_{4}$ bond elongation (1: 1.377(6); 1-K(crypt): 1.433(12) ave Å; Fig. S85†).

We sought to examine the generality of the trialkylborane Lewis acids to stabilize both the accumulated hydrides and other small molecules. Addition of $\mathrm{E}-\mathrm{H}$ substrates $\left(\mathrm{E}=\mathrm{NH}_{2}\right.$, NHMe, NHPh, OH, PHPh, SPh) to freshly thawed THF solutions of 1 afford 2-E as orange-tan powders with production of $\mathrm{H}_{2}$ (Fig. 4). ${ }^{26}$ 2-E are high-spin Fe(II)-species with solution magnetic susceptibilities ranging $\mu_{\text {eff }}=4.5-5.5 \mu_{\mathrm{B}}$ (THF, $25^{\circ} \mathrm{C}$ ). 2-OH and 2-PHPh provide diagnostic infrared handles with sharp $v_{(\mathrm{OH})} /$ $v_{(\mathrm{PH})}$ absorptions observed at 3630 and $2340 \mathrm{~cm}^{-1}(\mathrm{KBr})$, respectively-each consistent with previously reported $\mathrm{M}-\mathrm{OH}-$ $\mathrm{BR}_{3}{ }^{27}$ and Fe-phosphides. ${ }^{28}{ }^{1} \mathrm{H}$-NMR spectroscopy revealed 2NHMe, 2-NHPh, 2-OH, and 2-PHPh are $C_{2}$ symmetric in solution-consistent with Fe-E-B interactions remaining intact in solution. In contrast, 2-SPh exhibits a solution $C_{2 \mathrm{~V}}$ symmetric spectrum that broadens upon cooling to $-80{ }^{\circ} \mathrm{C}$, consistent with reversible B-S binding; likely a consequence of a weaker B-S interaction. ${ }^{29}$ This observation was supported by DFT analyses. In contrast to the strong B-O interaction in $\mathbf{2 - O H}$ (favored by $\sim 10 \mathrm{kcal}$ per mol per interaction), the calculated B-S interaction is thermodynamically disfavored by $\sim 9 \mathrm{kcal}$ per mol per interaction. In solution, the B-SPh binding equilibria in 2SPh were arrested by treating 2-SPh with two equiv. $\mathrm{NH}_{3}$. Competitive binding with $\mathrm{NH}_{3}$ afforded the ammonia-borane species, $\left({ }^{\mathrm{BBN}} \mathrm{PDP}^{t \mathrm{Bu}}\right) \mathrm{Fe}(\mathrm{SPh})_{2}\left(\mathrm{NH}_{3}\right)_{2}$ (3), highlighting the utility of moderately acidic groups to reversibly interact with small molecule substrates (Fig. 5).

To assess the structural similarities, 2-E were examined by XRD (Fig. 4). Each displays a pentacoordinate iron best described as distorted square-pyramidal with interacting trialkylboranes. The B-heteroatom distances range from 1.592(2)2.0504(19) $\AA$ following the trend $\mathrm{B}-\mathrm{OH}<\mathrm{B}-\mathrm{NHMe}<\mathrm{B}-\mathrm{NHPh}<$ $\mathrm{B}-\mathrm{PHPh}=\mathrm{B}-\mathrm{SPh}$. The same trend is observed for the Feheteroatom distance with 2-OH displaying the shortest bond (1.9812(13) ̊̊) and 2-PHPh/2-SPh displaying the longest bond

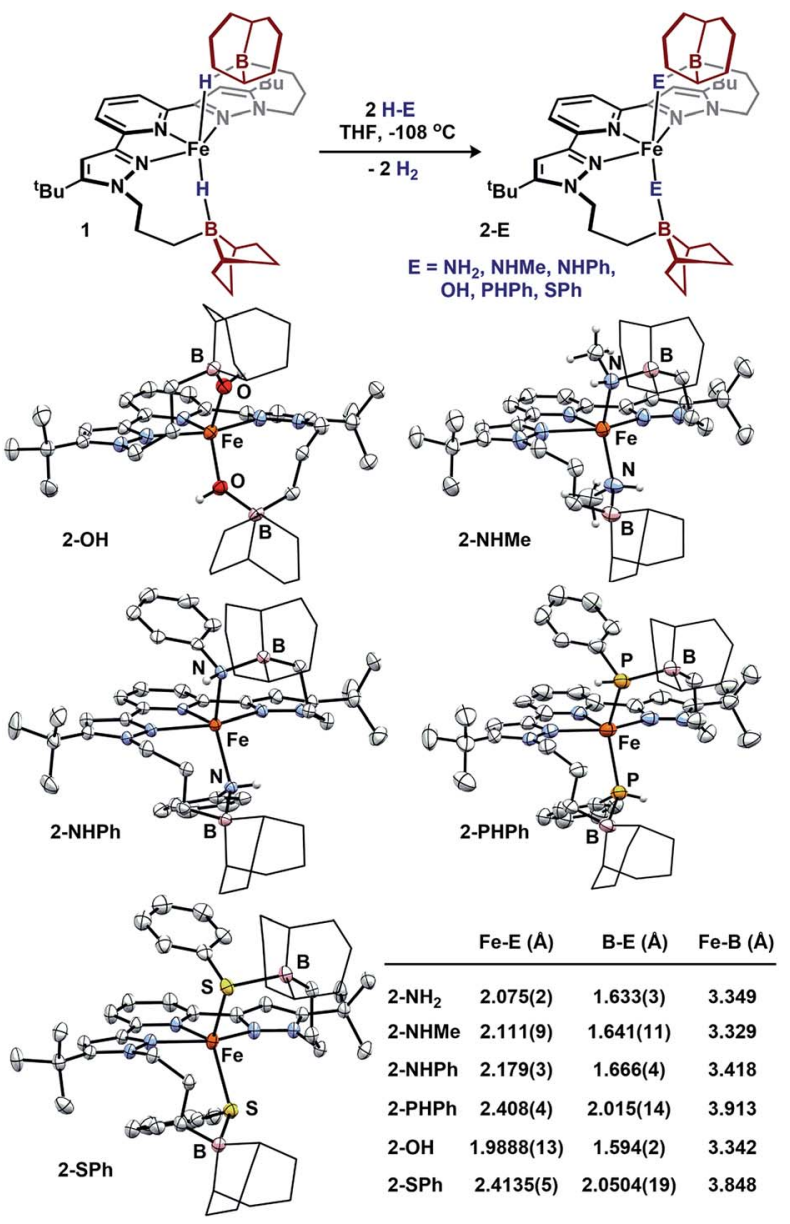

Fig. 4 Formation of 2-E and molecular structures (50\% probability ellipsoids) and averaged bond distances. For clarity, the 9-BBN substituents are displayed in wireframe.

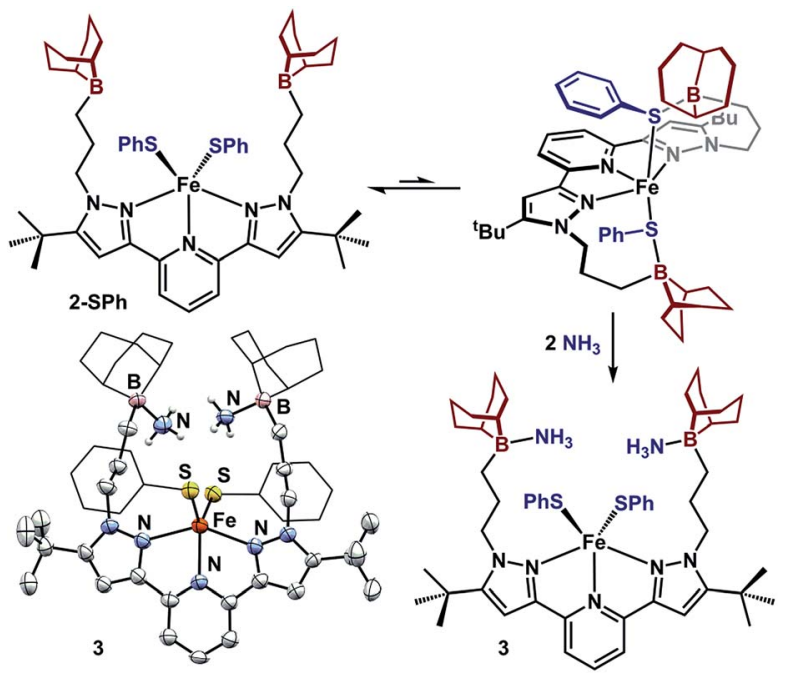

Fig. 5 Reversible acid/base interaction in 2-SPh and molecular structure of 3 (50\% probability ellipsoids). For clarity, the $9-\mathrm{BBN}$ and phenyl substituents are displayed in wireframe. 


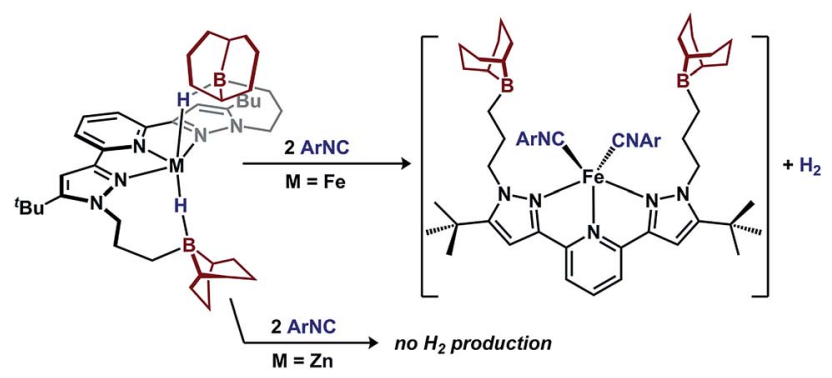

Fig. $6 \pi$-acid induced $\mathrm{H}_{2}$ extrusion from 1 .

(2.408(4) and 2.4134(5) $\AA$, respectively). The Fe-E bonds are longer than most reported examples, and we attribute this difference to due to quenching the ligand lone-pair by the trialkylborane. ${ }^{4 d, 19 b, 28,30}$ Upon substituting the B-S bond of 2-SPh with $\mathrm{NH}_{3}$ to afford 3, the Fe-S bond distance slightly decreases $(0.02 \AA)$ while the $\mathrm{Fe}-\mathrm{S}-\mathrm{Ph}$ angle expands (90.06(6) to $\left.110.5(3)_{\text {ave }}^{\circ}\right)$. The ability of the appended trialkylborane to stabilize various sizes of small molecules at the metal center is highlighted by comparing the Fe-B distances of $\mathbf{1}$ and 2-PHPh which vary by nearly $0.9 \AA$ (2.97 vs. $3.91 \AA)$. The isolation of 2-E highlights the utility of secondary coordination sphere interactions to not only stabilize hydrides at a metal center, but also to stabilize intermediate species following $\mathrm{H}_{2}$ loss. Attempts to synthesize most compounds analogous to 2-E from $\left({ }^{\mathrm{Bu}} \mathrm{PDP}^{t \mathrm{Bu}}\right)$ $\mathrm{FeBr}_{2}$ through established methods were unsuccessful (see ESI $\dagger) .{ }^{19 b, 28,30 b, 31}$ The $\left({ }^{\mathrm{Bu}} \mathrm{PDP}^{\mathrm{tBu}}\right) \mathrm{Fe}(\mathrm{SPh})_{2}$ complex was the only isolable compound, which is consistent with the observed stability of $\mathbf{3}$ in the absence of Lewis acid/base interactions.

The acid/base interactions can be viewed as an avenue for redox-leveling: the reduction potentials vary by $340 \mathrm{mV}$ across the series of compounds $\left(\mathbf{1}, 2-\mathrm{E}\right.$, and $\left({ }^{\mathrm{BBN}} \mathrm{PDP}^{t \mathrm{Bu}}\right) \mathrm{FeX}_{2}(\mathrm{X}=\mathrm{Cl}$, $\mathrm{Br}$ ); Table S3 $\dagger$ ) despite their disparate ligand donor properties. ${ }^{32}$ Upon sequestering the Lewis acid of 2-SPh with $\mathrm{NH}_{3}$ to form 3, the redox potential shifts more negative by $80 \mathrm{mV}(-2.21 \mathrm{~V} v s$. $\left.\mathrm{Fc} / \mathrm{Fc}^{+}\right)$. This modest shift is consistent with the weak or dynamic B-S interaction of 2-SPh. Further description of the Fe-E-B interactions were obtained from their DFT optimized structures. ${ }^{33}$ The LUMOs of the $\beta$ manifold for 2-E provide insight into their reduction potentials. ${ }^{34}$ The boron Lewis acids temper the donor properties of the X-type donor ligand, lowering their energy and percent composition in the frontier orbitals (see ESI $\dagger$ for details). The LUMOs of $\mathbf{1}$ and 2-E span a modest range of $0.51 \mathrm{eV}$. In contrast, their computationally investigated truncated $\left({ }^{\mathrm{Me}} \mathrm{PDP}^{t \mathrm{Bu}}\right) \mathrm{Fe}(\mathrm{E})_{2}$ counterparts range $1.72 \mathrm{eV}$. In analogy to the near constant operating potential for $\mathrm{N}_{2}$ reduction in nitrogenase where $\mathrm{H}^{-} / \mathrm{N}_{x} \mathrm{H}_{y}$ components are present throughout the sequence, the $\left[\left({ }^{\mathrm{BBN}} \mathrm{PDP}^{t \mathrm{Bu}}\right) \mathrm{Fe}\right]$ system accommodates small molecule substrates whose donor properties are regulated through Lewis acid/base interactions.

Given the unusual electronic and structural properties of $\mathbf{1}$, 1-K(crypt), and $\left({ }^{\mathrm{BBN}} \mathrm{PDP}^{\mathrm{tBu}}\right) \mathrm{ZnH}_{2}$, Wiberg bond-indices for were investigated for each of these complexes to gauge the bonding contribution of the $\mathrm{M}-\mathrm{H}-\mathrm{B}$ interaction (i.e. metal-hydride or metal-borohydride character). For each, the interaction is predominantly borohydride in character with $\mathrm{B}-\mathrm{H}$ indices ranging $0.65-0.78$ and $\mathrm{M}-\mathrm{H}$ indices ranging $0.14-0.22 .^{35}$ $\left({ }^{\mathrm{BBN}} \mathrm{PDP}^{t \mathrm{Bu}}\right) \mathrm{ZnH}_{2}$ displays the most $\mathrm{M}-\mathrm{H}$ character whereas 1K(crypt) displays the most B-H character-consistent with IR spectroscopy. While the data suggest the electronic structures are best described as borohydride, the $\mathrm{M}-\mathrm{H}$ character varies across the series, indicating $\mathrm{M}-\mathrm{H}$ reactivity may be accessible.

A key difference between metal-hydrides and borohydrides is the ability of the former to undergo reductive elimination. To test the hydride accumulation hypothesis, i.e. whether the bridging hydrides in $\mathbf{1}$ provide access to $\mathrm{Fe}(0)$ by eliminating $\mathrm{H}_{2}$, 1 was treated with a $\pi$-acid (Fig. 6). Addition of two equiv. 2,4,6tri-tert-butylphenylisocyanide to 1 expels $\mathrm{H}_{2}$ in 90(2)\% yield and affords $\left({ }^{\mathrm{BBN}} \mathrm{PDP}^{\mathrm{tBu}}\right) \mathrm{Fe}(\mathrm{CNAr})_{2} \cdot{ }^{36}$ In contrast, when subjecting the redox-inactive zinc variant, $\left({ }^{\mathrm{BBN}} \mathrm{PDP}^{t \mathrm{Bu}}\right) \mathrm{ZnH}_{2}$, to analogous conditions, only $7(3) \% \mathrm{H}_{2}$ was detected. These results implicate that $\mathbf{1}$ contains accessible $\mathrm{Fe}-\mathrm{H}$ character that is available for reactions. In contrast, the reactivity of $\left({ }^{\mathrm{BBN}} \mathrm{PDP}^{t \mathrm{tBu}}\right) \mathrm{ZnH}_{2}$ illustrates the inability to extrude $\mathrm{H}_{2}$ from a borohydride when access to a low-valent metal is not possible.

\section{Conclusions}

In summary, we have described a system capable of accumulating hydride equivalents at iron. Intramolecular borane Lewis acid serve a prominent role to not only impart stability to Fedihydrides, but also enable previously unobserved electronic structures at iron by regulating the Fe-X-type ligand interactions. Similarities can be drawn between our system and the $\mathrm{E}_{4}$ state of nitrogenase, where hydrides are accumulated at a near constant potential and addition of small molecule substrates induce $\mathrm{H}_{2}$ elimination concomitant with substrate stabilization. The geometric flexibility of the appended Lewis acids were previously shown to enable interactions both independent and cooperatively with a metal; here the geometric flexibility is highlighted by their ability to stabilize small molecules of varied sizes. Work is ongoing to interrogate how Lewis acids can be used to further regulate redox transformations at the metal.

\section{Conflicts of interest}

There are no conflicts to declare.

\section{Acknowledgements}

This work was supported by the NIH (1R01GM111486-01A1). N. K. S. is a Camille Dreyfus Teacher-Scholar. JJK is supported by the NIH NIGMS F32GM126635. We thank Suzanne Bart for EPR assistance. X-ray diffractometers were funded by the NSF (CHE 1625543).

\section{Notes and references}

1 (a) H. Dai and H. Guan, Iron Dihydride Complexes: Synthesis, Reactivity, and Catalytic Applications, Isr. J. Chem., 2017, 57, 1170-1203; (b) D. E. Prokopchuk, G. M. Chambers, E. D. Walter, M. T. Mock and 
R. M. Bullock, $\mathrm{H}_{2}$ Binding, Splitting, and Net Hydrogen Atom Transfer at a Paramagnetic Iron Complex, J. Am. Chem. Soc., 2019, 141, 1871-1876.

2 R. Y. Igarashi, M. Laryukhin, P. C. Dos Santos, H.-I. Lee, D. R. Dean, L. C. Seefeldt and B. M. Hoffman, Trapping HBound to the Nitrogenase FeMo-Cofactor Active Site during $\mathrm{H}_{2}$ Evolution: Characterization by ENDOR Spectroscopy, $J$. Am. Chem. Soc., 2005, 127, 6231-6241.

3 B. M. Hoffman, D. Lukoyanov, D. R. Dean and L. C. Seefeldt, Nitrogenase: A Draft Mechanism, Acc. Chem. Res., 2013, 46, 587-595.

4 (a) A. Jablonskytè, J. A. Wright, S. A. Fairhurst, J. N. T. Peck, S. K. Ibrahim, V. S. Oganesyan and C. J. Pickett, Paramagnetic Bridging Hydrides of Relevance to Catalytic Hydrogen Evolution at Metallosulfur Centers, J. Am. Chem. Soc., 2011, 133, 18606-18609; (b) W. Wang, M. J. Nilges, T. B. Rauchfuss and M. Stein, Isolation of a Mixed Valence Diiron Hydride: Evidence for a Spectator Hydride in Hydrogen Evolution Catalysis, J. Am. Chem. Soc., 2013, 135, 3633-3639; (c) R. A. Kinney, C. T. Saouma, J. C. Peters and B. M. Hoffman, Modeling the Signatures of Hydrides in Metalloenzymes: ENDOR Analysis of a Di-iron $\mathrm{Fe}(\mu-\mathrm{NH})(\mu-$ H)Fe Core, J. Am. Chem. Soc., 2012, 134, 12637-12647; (d) J. M. Smith, R. J. Lachicotte and P. L. Holland, NN Bond Cleavage by a Low-Coordinate Iron(II) Hydride Complex, $J$. Am. Chem. Soc., 2003, 125, 15752-15753; (e) J. Rittle, C. C. L. McCrory and J. C. Peters, A 106-Fold Enhancement in $\mathrm{N}_{2}$-Binding Affinity of an $\mathrm{Fe}_{2}(\mu-\mathrm{H})_{2}$ Core upon Reduction to a Mixed-Valence $\mathrm{Fe}^{\mathrm{II}} \mathrm{Fe}^{\mathrm{I}}$ State, J. Am. Chem. Soc., 2014, 136, 13853-13862.

5 (a) E. W. Dahl, J. J. Kiernicki, M. Zeller and N. K. Szymczak, Hydrogen Bonds Dictate $\mathrm{O}_{2}$ Capture and Release within a Zinc Tripod, J. Am. Chem. Soc., 2018, 140, 10075-10079; (b) E. W. Dahl, H. T. Dong and N. K. Szymczak, Phenylamino derivatives of tris(2-pyridylmethyl)amine: hydrogen-bonded peroxodicopper complexes, Chem. Commun., 2018, 54, 892-895; (c) C. M. Moore and N. K. Szymczak, Redox-induced fluoride ligand dissociation stabilized by intramolecular hydrogen bonding, Chem. Commun., 2015, 51, 5490-5492; (d) O. Tutusaus, C. Ni and N. K. Szymczak, A Transition Metal Lewis Acid/Base Triad System for Cooperative Substrate Binding, J. Am. Chem. Soc., 2013, 135, 3403-3406; (e) E. W. Dahl and N. K. Szymczak, Hydrogen Bonds Dictate the Coordination Geometry of Copper: Characterization of a Square-Planar Copper(I) Complex, Angew. Chem., Int. Ed., 2016, 55, 31013105.

6 (a) D.-H. Manz, P.-C. Duan, S. Dechert, S. Demeshko, R. Oswald, M. John, R. A. Mata and F. Meyer, Pairwise $\mathrm{H}_{2} /$ $\mathrm{D}_{2}$ Exchange and $\mathrm{H}_{2}$ Substitution at a Bimetallic Dinickel(II) Complex Featuring Two Terminal Hydrides, $J$. Am. Chem. Soc., 2017, 139, 16720-16731; (b) K. J. Anderton, B. J. Knight, A. L. Rheingold, K. A. Abboud, R. GarcíaSerres and L. J. Murray, Reactivity of hydride bridges in a high-spin $\left[\mathrm{Fe}_{3}(\mu-\mathrm{H})_{3}\right]^{3+}$ cluster: reversible $\mathrm{H}_{2} / \mathrm{CO}$ exchange and $\mathrm{Fe}-\mathrm{H} / \mathrm{B}-\mathrm{F}$ bond metathesis, Chem. Sci., 2017, 8, 41234129; (c) Y. Yu, A. R. Sadique, J. M. Smith, T. R. Dugan,
R. E. Cowley, W. W. Brennessel, C. J. Flaschenriem, E. Bill, T. R. Cundari and P. L. Holland, The Reactivity Patterns of Low-Coordinate Iron-Hydride Complexes, J. Am. Chem. Soc., 2008, 130, 6624-6638.

7 J. J. Kiernicki, M. Zeller and N. K. Szymczak, Hydrazine Capture and $\mathrm{N}-\mathrm{N}$ Bond Cleavage at Iron Enabled by Flexible Appended Lewis Acids, J. Am. Chem. Soc., 2017, 139, 18194-18197.

8 (a) M. A. Nesbit, D. L. M. Suess and J. C. Peters, E-H Bond Activations and Hydrosilylation Catalysis with Iron and Cobalt Metalloboranes, Organometallics, 2015, 34, 47414752; (b) D. L. M. Suess and J. C. Peters, H-H and $\mathrm{Si}-\mathrm{H}$ Bond Addition to $\mathrm{Fe} \equiv \mathrm{NNR}_{2}$ Intermediates Derived from $\mathrm{N}_{2}$, J. Am. Chem. Soc., 2013, 135, 4938-4941; (c) E. Alberico, P. Sponholz, C. Cordes, M. Nielsen, H.-J. Drexler, W. Baumann, H. Junge and M. Beller, Selective Hydrogen Production from Methanol with a Defined Iron Pincer Catalyst under Mild Conditions, Angew. Chem., Int. Ed., 2013, 52, 14162-14166; (d) R. Bau, H. S. H. Yuan, M. V. Baker and L. D. Field, An X-ray study of $\mathrm{FeH}(\mathrm{dmpe})_{2}\left(\mathrm{BH}_{4}\right)$ : a compound containing a singly-bridged $\mathrm{BH}_{4}$ ligand with a bent $\mathrm{Fe}-\mathrm{H}-\mathrm{B}$ linkage, Inorg. Chim. Acta, 1986, 114, L27-L28; (e) D. L. M. Suess and J. C. Peters, A CO-Derived Iron Dicarbyne That Releases Olefin upon Hydrogenation, J. Am. Chem. Soc., 2013, 135, 12580-12583.

9 (a) J. S. Figueroa, J. G. Melnick and G. Parkin, Reactivity of the Metal $\rightarrow \mathrm{BX}_{3}$ Dative $\sigma$-Bond: 1,2-Addition Reactions of the $\mathrm{Fe} \rightarrow \mathrm{BX}_{3}$ Moiety of the Ferraboratrane Complex $\left[\kappa^{4}\right.$ $\left.\mathrm{B}(\mathrm{mimBut})_{3}\right] \mathrm{Fe}(\mathrm{CO})_{2}$, Inorg. Chem., 2006, 45, 7056-7058; (b) C. Kimblin, D. G. Churchill, B. M. Bridgewater, J. N. Girard, D. A. Quarless and G. Parkin, Tris(mercaptoimidazolyl)hydroborato complexes of cobalt and iron, $[\mathrm{TmPh}]_{2} \mathrm{M}(\mathrm{M}=\mathrm{Fe}, \mathrm{Co})$ : structural comparisons with their tris(pyrazolyl)hydroborato counterparts, Polyhedron, 2001, 20, 1891-1896; (c) See ESI Table S21 $\dagger$ for further literature comparisons to $\mathrm{Fe}-\mathrm{B}$ bond distances and $v(\mathrm{Fe}-\mathrm{H}-\mathrm{B})$ vibrational data.

$10 \mathrm{~B}-\mathrm{H}$ coupling is not observed presumably due to low symmetry at boron.

11 Attempts at deuterium labeling 1 with LiBDEt $_{3}$ were unsuccessful.

12 S. Marks, R. Köppe, T. K. Panda and P. W. Roesky, Unprecedented Zinc-Borane Complexes, Chem.-Eur. J., 2010, 16, 7096-7100.

13 Potentials were assessed by square wave voltammetry.

14 A typical shift of $200-300 \mathrm{mV}$ is expected per $\mathrm{Cl} / \mathrm{H}$ substitution, see: (a) T. Liu, D. L. DuBois and R. M. Bullock, An iron complex with pendent amines as a molecular electrocatalyst for oxidation of hydrogen, Nat. Chem., 2013, 5, 228; (b) M. Tilset, I. Fjeldahl, J.-R. Hamon, P. Hamon, L. Toupet, J.-Y. Saillard, K. Costuas and A. Haynes, Theoretical, Thermodynamic, Spectroscopic, and Structural Studies of the Consequences of OneElectron Oxidation on the $\mathrm{Fe}-\mathrm{X}$ Bonds in 17- and 18Electron $\mathrm{Cp}^{*} \mathrm{Fe}(\mathrm{dppe}) \mathrm{X}$ Complexes (X $=\mathrm{F}, \mathrm{Cl}, \mathrm{Br}, \mathrm{I}, \mathrm{H}$, $\mathrm{CH}_{3}$ ), J. Am. Chem. Soc., 2001, 123, 9984-10000; (c) Y. Hu, L. Li, A. P. Shaw, J. R. Norton, W. Sattler and Y. Rong, 
Synthesis, Electrochemistry, and Reactivity of New Iridium(III) and Rhodium(III) Hydrides, Organometallics, 2012, 31, 5058-5064; (d) A. P. Shaw, J. R. Norton, D. Buccella, L. A. Sites, S. S. Kleinbach, D. A. Jarem, K. M. Bocage and C. Nataro, Synthesis, Electrochemistry, and Reactivity of Half-Sandwich Ruthenium Complexes Bearing Metallocene-Based Bisphosphines, Organometallics, 2009, 28, 3804-3814.

15 B. J. McNicholas, R. H. Grubbs, J. R. Winkler, H. B. Gray and E. Despagnet-Ayoub, Tuning the formal potential of ferrocyanide over a $2.1 \mathrm{~V}$ range, Chem. Sci., 2019, 10, 36233626.

16 Crown ethers are not required to isolate the reduced Fedi(boro)hydride, see ESI. $\dagger$

17 Y. Nakajima, Y. Nakao, S. Sakaki, Y. Tamada, T. Ono and F. Ozawa, Electronic Structure of Four-Coordinate Iron(I) Complex Supported by a Bis(phosphaethenyl)pyridine Ligand, J. Am. Chem. Soc., 2010, 132, 9934-9936.

18 (a) A. V. Polezhaev, C. J. Liss, J. Telser, C.-H. Chen and K. G. Caulton, A PNNH Pincer Ligand Allows Access to Monovalent Iron, Chem.-Eur. J., 2018, 24, 1330-1341; (b) C. E. MacBeth, S. B. Harkins and J. C. Peters, Synthesis and characterization of cationic iron complexes supported by the neutral ligands $\mathrm{NPi}-\mathrm{Pr}_{3}, \mathrm{NArPi}-\mathrm{Pr}_{3}$, and $\mathrm{NSt}-\mathrm{Bu}_{3}$, Can. J. Chem., 2005, 83, 332-340; (c) C. V. Thompson, I. Davis, J. A. DeGayner, H. D. Arman and Z. J. Tonzetich, Iron Pincer Complexes Incorporating Bipyridine: A Strategy for Stabilization of Reactive Species, Organometallics, 2017, 36, 4928-4935; (d) N. Ehrlich, M. Kreye, D. Baabe, P. Schweyen, M. Freytag, P. G. Jones and M. D. Walter, Synthesis and Electronic Ground-State Properties of Pyrrolyl-Based Iron Pincer Complexes: Revisited, Inorg. Chem., 2017, 56, 8415-8422.

19 (a) A. McSkimming and W. H. Harman, A Terminal $\mathrm{N}_{2}$ Complex of High-Spin Iron(I) in a Weak, Trigonal Ligand Field, J. Am. Chem. Soc., 2015, 137, 8940-8943; (b) J. S. Anderson, M.-E. Moret and J. C. Peters, Conversion of $\mathrm{Fe}-\mathrm{NH}_{2}$ to $\mathrm{Fe}-\mathrm{N}_{2}$ with release of $\mathrm{NH}_{3}$, J. Am. Chem. Soc., 2013, 135, 534-537; (c) P. P. Samuel, K. C. Mondal, N. Amin Sk, H. W. Roesky, E. Carl, R. Neufeld, D. Stalke, S. Demeshko, F. Meyer, L. Ungur, L. F. Chibotaru, J. Christian, V. Ramachandran, J. van Tol and N. S. Dalal, Electronic Structure and Slow Magnetic Relaxation of LowCoordinate Cyclic Alkyl(amino) Carbene Stabilized Iron(I) Complexes, J. Am. Chem. Soc., 2014, 136, 11964-11971; (d) S. A. Stoian, Y. Yu, J. M. Smith, P. L. Holland, E. L. Bominaar and E. Münck, Mössbauer, Electron Paramagnetic Resonance, and Crystallographic Characterization of a High-Spin $\mathrm{Fe}(\mathrm{I})$ Diketiminate Complex with Orbital Degeneracy, Inorg. Chem., 2005, 44, 4915-4922; (e) K. P. Chiang, C. C. Scarborough, M. Horitani, N. S. Lees, K. Ding, T. R. Dugan, W. W. Brennessel, E. Bill, B. M. Hoffman and P. L. Holland, Characterization of the $\mathrm{Fe}-\mathrm{H}$ Bond in a Three-Coordinate Terminal Hydride Complex of Iron(I), Angew. Chem., Int. Ed., 2012, 51, 3658-3662.

$20 \mathrm{~g}$-Values were obtained by simulation, see ESI. $\dagger$
21 (a) Z. Ouyang, J. Du, L. Wang, J. L. Kneebone, M. L. Neidig and L. Deng, Linear and T-Shaped Iron(I) Complexes Supported by N-Heterocyclic Carbene Ligands: Synthesis and Structure Characterization, Inorg. Chem., 2015, 54, 8808-8816; (b) M. I. Lipschutz, T. Chantarojsiri, Y. Dong and T. D. Tilley, Synthesis, Characterization, and Alkyne Trimerization Catalysis of a Heteroleptic Two-Coordinate Fe $^{\mathrm{I}}$ Complex, J. Am. Chem. Soc., 2015, 137, 6366-6372.

22 The pyridine(dipyrazole) framework has not been observed to act as a redox-active ligand, see B. J. Cook, C.-H. Chen, M. Pink, R. L. Lord and K. G. Caulton, Inorg. Chim. Acta, 2016, 451, 82-91. It has been proposed as an intermediate species before, see T. J. Sherbow, J. C. Fettinger and L. A. Berben, Inorg. Chem., 2017, 56, 8651-8660.

23 See ESI $\dagger$ for comparison between alternative spin configurations.

24 (a) A. M. Tondreau, S. C. E. Stieber, C. Milsmann, E. Lobkovsky, T. Weyhermüller, S. P. Semproni and P. J. Chirik, Oxidation and Reduction of Bis(imino)pyridine Iron Dinitrogen Complexes: Evidence for Formation of a Chelate Trianion, Inorg. Chem., 2013, 52, 635-646; (b) S. K. Russell, A. C. Bowman, E. Lobkovsky, K. Wieghardt and P. J. Chirik, Synthesis and Electronic Structure of Reduced Bis(imino)pyridine Manganese Compounds, Eur. J. Inorg. Chem., 2012, 2012, 535-545.

25 Q. Knijnenburg, S. Gambarotta and P. H. M. Budzelaar, Ligand-centred reactivity in diiminepyridine complexes, Dalton Trans., 2006, 5442-5448.

26 Protonolysis reactions with 1-K(crypt) resulted in disproportionation. Treating 1 with a diatom surrogate, $\mathrm{Me}_{3} \mathrm{SiCN}$, affords dimeric $\left[\left({ }^{\mathrm{BBN}} \mathrm{PDP}^{t \mathrm{Bu}}\right) \mathrm{Fe}(\mathrm{NC})_{2}\right]_{2}$, see ESI. $\dagger$

27 (a) B. L. Conley and T. J. Williams, Thermochemistry and Molecular Structure of a Remarkable Agostic Interaction in a Heterobifunctional Ruthenium-Boron Complex, J. Am. Chem. Soc., 2010, 132, 1764-1765; (b) R. Choukroun, C. Lorber, L. Vendier and C. Lepetit, Vanadocene-Mediated Ionization of Water in the Aqua Species $\left[\mathrm{H}_{2} \mathrm{O} \cdot \mathrm{B}\left(\mathrm{C}_{6} \mathrm{~F}_{5}\right)_{3}\right]$ : Structural Characterization of the Hydride and Hydroxide Complexes $\left[\mathrm{Cp}_{2} \mathrm{~V}(\mu-\mathrm{H}) \mathrm{B}\left(\mathrm{C}_{6} \mathrm{~F}_{5}\right)_{3}\right]$ and $\left[\mathrm{Cp}_{2} \mathrm{~V}(\mu-\mathrm{OH}) \mathrm{B}\left(\mathrm{C}_{6} \mathrm{~F}_{5}\right)_{3}\right]$, Organometallics, 2006, 25, 1551-1553; (c) N. Tsoureas and A. A. Danopoulos, Pyridyl- and diphenylphosphinoethylfunctionalised $\mathrm{N}$-heterocyclic carbene platinum methyl complexes, J. Organomet. Chem., 2015, 775, 178-187.

28 A. K. Hickey, S. B. Muñoz, S. A. Lutz, M. Pink, C.-H. Chen and J. M. Smith, Arrested $\alpha$-hydride migration activates a phosphido ligand for $\mathrm{C}-\mathrm{H}$ insertion, Chem. Commun., 2017, 53, 412-415.

29 2-SPh and the zinc analogue can be prepared from the reaction of $\left({ }^{\mathrm{BBN}} \mathrm{PDP}^{t \mathrm{Bu}}\right) \mathrm{MH}_{2}$ with $\mathrm{PhSSPh}$. Both reactions extrude $\mathrm{H}_{2}$, see ESI. $\dagger$

30 (a) S. E. Creutz and J. C. Peters, Exploring secondary-sphere interactions in $\mathrm{Fe}-\mathrm{N}_{x} \mathrm{H}_{y}$ complexes relevant to $\mathrm{N}_{2}$ fixation, Chem. Sci., 2017, 8, 2321-2328; (b) Y. M. Badiei, M. A. Siegler and D. P. Goldberg, $\mathrm{O}_{2}$ Activation by Bis(imino)pyridine Iron(II)-Thiolate Complexes, J. Am. Chem. Soc., 2011, 133, 1274-1277. 
31 N. A. Eckert, J. M. Smith, R. J. Lachicotte and P. L. Holland, Low-Coordinate Iron(II) Amido Complexes of $\beta$ Diketiminates: Synthesis, Structure, and Reactivity, Inorg. Chem., 2004, 43, 3306-3321.

32 (a) R. D. Bemowski, A. K. Singh, B. J. Bajorek, Y. DePorre and A. L. Odom, Effective donor abilities of E-t-Bu and EPh $(\mathrm{E}=$ $\mathrm{O}, \mathrm{S}, \mathrm{Se}, \mathrm{Te})$ to a high valent transition metal, Dalton Trans., 2014, 43, 12299-12305; (b) S. A. DiFranco, N. A. Maciulis, R. J. Staples, R. J. Batrice and A. L. Odom, Evaluation of Donor and Steric Properties of Anionic Ligands on High Valent Transition Metals, Inorg. Chem., 2012, 51, 1187-1200.

33 Analysis of the LUMO's were used in lieu of the optimized reduced complexes of 2-E and truncated variants because (1) the reorganization of $\mathbf{1}$ upon reduction is minimal, (2) the high correlation between the $\beta$-LUMO of 1 and the $\beta$ SOMO of 1-K(crypt), see Fig. S88. $\dagger$ An analysis LUMO energies and calculated reduction potentials or a subset of $\mathbf{1}$ and 2-E is included in the ESI. $\dagger$
34 (a) D. D. Méndez-Hernández, J. G. Gillmore, L. A. Montano, D. Gust, T. A. Moore, A. L. Moore and V. Mujica, Building and testing correlations for the estimation of one-electron reduction potentials of a diverse set of organic molecules, J. Phys. Org. Chem., 2015, 28, 320-328; (b) J. R. Levin, W. L. Dorfner, A. X. Dai, P. J. Carroll and E. J. Schelter, Density Functional Theory as a Predictive Tool for Cerium Redox Properties in Nonaqueous Solvents, Inorg. Chem., 2016, 55, 12651-12659.

35 (a) R. Hoffmann, P. von Ragué Schleyer and H. F. Schaefer III, Predicting Molecules-More Realism, Please!, Angew. Chem., Int. Ed., 2008, 47, 7164-7167; (b) The truncated analogue, $\left({ }^{\mathrm{Me}} \mathrm{PDP}^{t \mathrm{Bu}}\right) \mathrm{FeH}_{2}$, is calculated to have a $\mathrm{M}-\mathrm{H}$ bond index of 0.65 .

36 The assignment of $\left({ }^{\mathrm{BBN}} \mathrm{PDP}^{t \mathrm{Bu}}\right) \mathrm{Fe}(\mathrm{CNAr})_{2}$ is based on ${ }^{1} \mathrm{H}$ NMR and IR spectroscopies as well as MALDI mass spectrometry. We have been unable to isolate analytically pure samples of this species due to its high solubility. 